\title{
On the Practice of 'Algorithm Analysis and Design' Course Based on Blackboard Platform
}

\author{
Bangzuo Zhang, Yanlin Zheng \\ School of computer science and information technology \\ Northeast Normal University \\ Changchun, China \\ zhangbz@nenu.edu.cn, zhengyl@nenu.edu.cn
}

\author{
Qinghua Liu, Xijin Fu \\ Library \\ Northeast Normal University \\ Changchun, China \\ liuqh@nenu.edu.cn, fuxj@nenu.edu.cn
}

\begin{abstract}
Algorithm Analysis and Design is one of the core courses in the major of Computer Science and Technology. In the traditional teaching process, practical teaching is difficult to manage, test and evaluate. As one sort of effective teaching method, Blackboard (Bb) platform provides opportunities for the improvement of practical teaching. Under the benefit of the vigorous promotion in the university, the preliminary exploration of Bb platform's application was firstly carried out. Based on the $\mathrm{Bb}$ platform, the main practices cover the following parts: (1) the diverse learning process management; (2) the academic evaluation and feedback; (3) the grade management. Finally, throughout two years' practicing in this course, the comparison of the average grade of undergraduate students initially shows that the use of $\mathrm{Bb}$ platform has apparent effectiveness for the practical teaching.
\end{abstract}

Keywords-Blackboard (Bb) platform; practical teaching; constructivism learning theory;

\section{INTRODUCTION}

The Blackboard platform is a virtual learning environment and course management system developed by Blackboard Inc, which is popularly utilized in the higher education system. The first author initially knew it in 2012, when he was a visiting scholar in the University of Illinois at Chicago. During that time, he had sat in a few undergraduate courses, and observed that students had learnt courses by it before the class or submitted homework after the class. When he came back, he learnt that this university has introduced the platform and put into trial as early as 2009. In the spring semester of 2013, when he taught the course of Algorithm Analysis and Design, the thought of using the $\mathrm{Bb}$ platform as the auxiliary teaching method immediately came into his mind, especially for the key points and difficult points of practical teaching.

Algorithm Analysis and Design is one of the core courses for any undergraduate student in the major of Computer Science and Technology [1]. It's typically meant for students who already have some introductory knowledge of programming and data structures. The course covers the basic foundations of designing correct and efficient sequential algorithm, through a process of mathematical analysis and logical design steps, which can be translated to software programs for effective deployment in practice. Therefore, the course fully embodies the three processes of computer science-theory, abstract and design, and requires both theory and practice in teaching. The theoretical part can be better accomplished in the classroom, but the practical teaching is always a headache problem, in particular, how to manage, test and evaluate is always the difficulty part of this kind of courses [2].

Concerning how to conduct practical teaching, the authors have been exploring for many years. At the beginning, they take it as other experimental curriculum and design experiments for students, which require students to hand in the uniform experimental report paper. It's a painful process not only for students but also for the teachers. For students, they had to write down the source code, for teachers, they had to spend more time to correct students' papers and record the sores, which almost took nearly two days for one experiment. While, at the end of the semester, facing with the thick experiment reports from the students, the authors can't be sure about their real learning results and sort out the real teaching effect. Even, how to save these reports is a thorny problem. The authors have also tried to use the mailbox to distribute and collect the homework. There are also many problems of making these reports and managing the results, for example, before the deadline, numerous submissions paralyzed the mailbox system and several students' assignment was lost thanks to the email trouble. The authors also tried to use Online Judge system similar to the ACM competition, but the detection system of OJ sometimes were too harsh so that almost all of the experiment source codes the students had written were very difficult to pass all the test sample sets. As a consequence, students felt a great sense of frustration, and gradually lost their learning interest.

Like many other teachers, at the beginning of using the $\mathrm{Bb}$ platform, the authors thought it was just another teaching resource sharing platform, or some electronic homework assignment and submission system, and only used to upload teaching resources, curriculum content, send message and share slides. The authors had reposted the course of Introduction to Algorithm, the open course from the Massachusetts Institute of Technology (MIT), the capacity reached nearly 6G. However, according to the statistic, most students only read the first video, there was rare people see the $2^{\text {nd }}$ one. This resource was the most famous open class in the world, but students didn't choose to read it, the authors were so surprised by the fact. Although a good resource is important, the method and mechanism to properly guide the students to achieve effective learning is more important. 
After the training of library, the authors have a new thought that using the $\mathrm{Bb}$ platform to provide a lot of support tools, a variety of teaching methods, which not only offers the basic tools of a common platform, as well as some surprising tools, but also supplies many different services. The operation is simple that moves mouse to achieve it easily. From the perspective of constructivism, the authors have to say that the $\mathrm{Bb}$ platform is a good educational support environment. It is above an excellent teaching resources platform for teachers and students [3].

The authors have used $\mathrm{Bb}$ platform on practical teaching of Algorithm Analysis and Design for about two years, and been aware of its convenience. Therefore, from the angle of constructivism theory [4], the authors tried to use the wealth of pedagogical tools of $\mathrm{Bb}$ platform to realize students' learning process management [5], procedural learning evaluation and feedback [6], final performance management, in order to support a mostly true, active, cooperate constructive and meaningful learning environment, which well solved the problem of traditional learning process, like being uncontrollable, difficult to evaluate, bad effect etc. The obvious comparison of students' marks of these two years proved that it obtained good teaching effect and won universal praise.

This paper summarizes the main practices the authors have done. The learning process management is in Section 2, the evaluation and feedback is in Section 3, and the performance management is in Section 4, respectively. In Section 5, the authors compare the teaching effect of the work of these two years. Conclusion is in Section 6.

\section{The LEARning Process MANAGEMENT}

The $\mathrm{Bb}$ platform offers a variety of learning methods and different tools for teachers to manage the learning process. Considering the characteristic of this course, the practical teaching mainly uses the online assignment, test, and curriculum design, etc., which are the good tools to manage the learning process.

For this course, the online assignments are done regularly once a week, totally about 15 times in each semester. Each time there are two programming tasks, which correspond to the content of classroom teaching. The authors assigned them with the assignment tool, which can control the learning process easily and have several functions, such as it can set the task to single student or a group of students, set the task content that prepared before when to visible and when to available, set the task display time, submission end time, the track tempt details and grade function. The teachers can overall control the progress of student's submission, and create a good learning environment, guide and emphasize the process management of learning.

Taking into account the different learning levels of students, the authors usually assign several similar tasks, which belong to the student with the same knowledge points but different in the learning level. The student can choose one according to his/her own ability. In this course, the introduction content is sort, it's also the most basic algorithm, the authors consider to the different starting point of the students, in $2^{\text {nd }}$ online assignment, usually there are these two assignments, one is merge sort, and the other is quick sort. The merge sort provides three options:

(1) using recursive procedure,

(2) eliminating recursion,

(3) using natural merge.

For quick sort, the key point is the pivot element choosing for the partition process, so the authors provides five options, the pivot is:

(1) the $1^{\text {st }}$ element,

(2) the last element,

(3) the middle element,

(4) the randomly selected element,

(5) the median of a set of 3 elements randomly selected.

They are different in the levels of difficulty for each case, the starting point is the classical method in the textbook, which in fact only needs to imitate, so the discrimination ability is very obvious, and can well meet the beginning of the curriculum content.

In order to know what level students have mastered of the basic knowledge, the authors add the unit test in each unit. The questions are single and multiple choices, or determine true/false. Students can do self assessment freely online to know their own level. The test database will increase gradually in the process of teaching.

To exercise the students' comprehensive application ability of the algorithm analysis and design, a curriculum design should be assigned in the middle of the semester, like a project. Every student can choose a question and give some different kinds of solutions, which are usually above 3 kinds. The design requires the students to learn how to integrate different knowledge in different ways to solve the same problem, enhance the application and comparison of the knowledge of this course.

With the help of related tools provided by the $\mathrm{Bb}$ platform, the authors can integrate the course and the students' actual condition to effectively control of the learning process, which better controls the students' learning progress, and has better teaching effectiveness.

\section{EVALUATION AND FEEDBACK}

Academic evaluation is one of the main parts of the teaching. It is very important to know the student's learning situation, discover the teaching problems, and optimize the teaching strategies. The Bb platform provides an interactive environment on the learning process for the students and the teachers, and makes the learning an active construction process.

Since design is one of the important content in this course, the online assignments require students to program with $\mathrm{C} / \mathrm{C}++$ language. Evaluation is the important key function. In order to train the students' good programming style, the authors require students to not only submit the algorithm source code, but also corresponding notes to make a brief problem solving report.

It's been a long way to evaluate and correct the students' assignments. In order to simplify the evaluation process, the authors usually follow the way of online judge system for ACM competition and build a uniform template to realize the near automatic judge. The authors fixed the program 
automatically in the specified location to read the test sample set, and set the local corresponding programming environment to achieve a near automatic program evaluation process. When the authors click to download the source code, the source code can be automatically imported and run in the compiler environment, and automatically read the test case that has been set. According to the running result, the authors give the score and reviews from the template. The whole process runs smoothly, and completes in a few seconds, greatly speeding up the correcting process. For 100 students, now it can complete in less than 3 hours, while, in the past it would take about 2 days by hand. Of course, the authors also hope that $\mathrm{Bb}$ platform may provide a packaged application for programming problem, allow the users to set once and can be run automatically without to limit the user program template.

$\mathrm{Bb}$ platform also provides the function of feedback on students' assignment. Teachers can give students a message to review the assignment. Usually, in order to speed up the pace, the authors would set a review template, which gives the description for each test case, an example shown in figure 1. Students can also access the system, check their grades, read the teacher's message, and revise their program and submit again. In fact, students sometime submit the program repeatedly until it is completely correct. So far, up to a maximum of 5 times, it would be a problem that the students would have multiple different grades, and the system would be retained them all, so teachers have to manually delete or ignore others and determine the final scores, this is another function that the authors hope $\mathrm{Bb}$ platform can be improved.
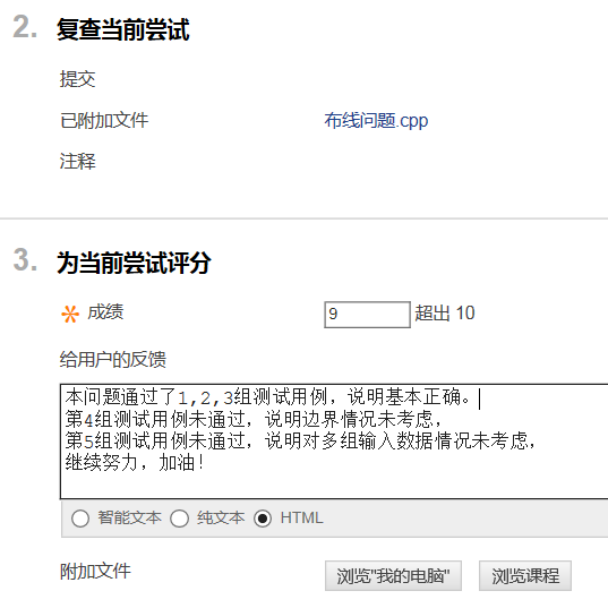

Figure 1. Example of teachers review the assignment.

For the improvement of students' participation and interaction, the authors use the forum tool to establish a forum for the students to communicate about the assignment. They can post their program, ask some questions, and freely discussed. For guiding the discussion in the forum, the authors erect the excellent assignment system. Some better assignments, from 3 to 5 students, are elected each week and required to post in the forum, including different design strategies, implementing methods, which encourages student to learn from each other and promotes them to rise jointly. Because there is no standard answer in the algorithm design, the student can make the comparison of a variety of solutions, the authors consciously choose a variety of excellent assignments, make every student learn multiple solutions of the same problem, and learn through the many outstanding students programs to improve their abilities of algorithm design. An example is shown in Figure 2.

For this course, in order to strengthen the introduction and hear the students' feedback, the authors have arranged a survey in the beginning and middle of the semester. In the beginning, it is a key time to introduce the content, so the authors have assigned a survey that requires students to collect the course situation that open this lesson domestic and foreign country, the outstanding teaching team, curriculum and course content that are widely used in their life, to improve the students' understanding of the content and prompt the learning interest. In the middle of semester, the authors have assigned another survey that mainly collected the feedback from the students to understand the specific learning situation, which improves the students' sense of participation, as well as makes the teaching better.

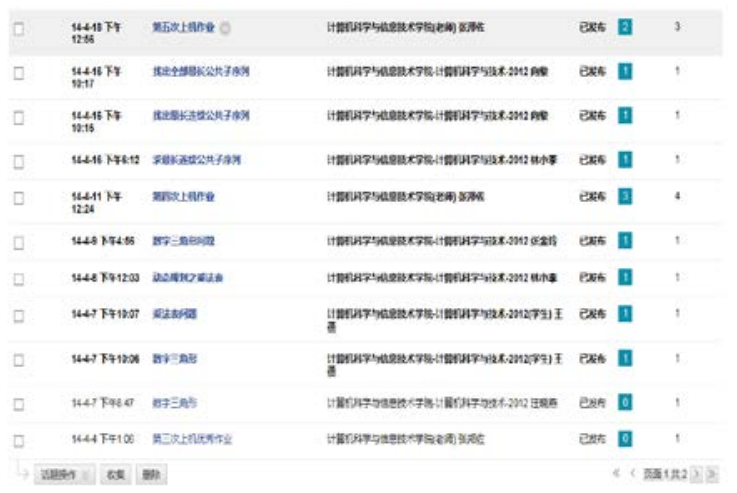

Figure 2. Example of student forum

\section{PERFormance MANAGEMENT}

The student achievement management is also an important component of the teaching process. Usually, the students' grades include general performance such as attendance, assignments and class performance, and the last examination scores. But it is very difficult to evaluate, record and management in manual labor. So many teachers still only use the last examination scores. It is not fair for the majority of average students, because one score can't well distinguish the students' performance, which is unfair and discourage to the students that study hard, but not good at examination, and some other students that usually do not study hard, often skip class, only need to review before examination and feel confident.

And now, more and more university requires providing diversified assessment scores for student. But the learning process is so difficult to determine and manage. Fortunately, $\mathrm{Bb}$ platform provides a convenience for the grade evaluation and management. The students' achievement system automatically retained every record, and provides data 
collection and statistics function. It not only saves much time, but also reduces the possibility of error, providing an efficient and fair environment.

The screenshot of student grades management for spring semester, 2014 is in Figure 3. There are currently 12 online assignments, 2 tasks each, and total of 24 tasks. 10 points for each task, so the total score is 240 points, with 100 points for the curriculum design, and the total is 340 . It is $30 \%$ for the final total grade. So, each student can know his/her general performance in time. It also can urge the students to take the initiative to finish the assignment and they can submit again and again for a better mark if the score is not ideal. The teacher can also derive directly the data as a basis of general performance into the final total grade.

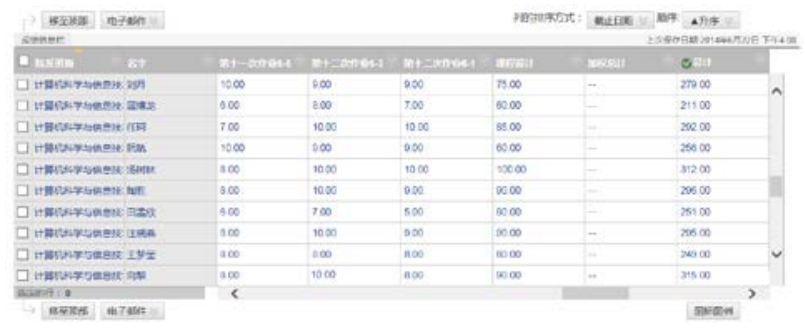

Figure 3. student achievement management in spring semester, 2014

\section{The Teaching EfFect Preliminary analysis}

The students' average grades on the online assignment of the last two years, from 2013 to 2014, are summarized to explain the teaching effect of this course with the $\mathrm{Bb}$ platform. The teaching conditions are basically the same, while in the strict sense it isn't the control experiment, but is basically comparable. The authors selected 21 tasks in the practical teaching, which are basically the same question, and the average grades of students are compared, the effect shown in Figure 4, initially revealed the effectiveness of the practical teaching based on Bb platform. In 2014, the total number of the students' average grade is higher than that of 2013 is 13 , nearly to $62 \%$. In 2013, the students' average grade is 8.47, while in 2014 is up to 8.71, which has increased $3 \%$.

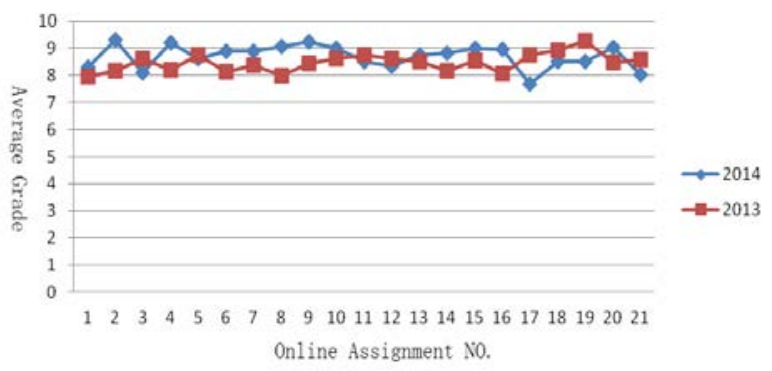

Figure 4. comparison of students' average grade of online asignment in 2013, 2014 year
In the spring semester in 2013, the authors firstly use the $\mathrm{Bb}$ platform, only as the students' online assignment submission tool, beyond other works. In 2014, the authors carried on construction the corresponding item, and paid more attention on the combination of the online assignment in the $\mathrm{Bb}$ platform and offline teaching in the classroom. And the result was improved. From the students' grade, the grade in 2014 had obvious landslide in the last 5 online assignment task, which also reminded the authors to improve in the corresponding part in the later teaching process.

\section{THE CONCLUSION}

Facing the hard question of practical teaching of the Algorithm Analysis and Design course with the help of the $\mathrm{Bb}$ platform, the authors stand on the perspective of constructivism learning theory and explore the diversification learning process management, the nearly automatically evaluation and feedback and the performance management. And the result of comparing the students' average grades in the last two years to indicate the effectiveness of teaching. Of course, the authors will try other educational concepts and techniques, such as flipping classroom [7], and applied in the teaching process, and constantly improve the teaching effect.

Due to the usage of the $\mathrm{Bb}$ platform is short, many functions that has been provided don't use freely, the authors will keep on exploring a lot more. Above is a brief description of what the authors have done, and the authors will try their best to make the better wok in the future.

\section{ACKNOWLEDGMENT}

Educational Administration Department of the university gives great support and encourages the authors to persist in this research. The authors would like to say thanks. The authors also would like to thank the leaders and staff of the subject service group of the university library. For these two years, they have provided all kinds of help in terms of curriculum organization and technical support. Since their silent dedication and support, the course contents and teaching methods are constantly expanding and enriching and the authors also have so many inspiration and harvest in this paper.

This work is supported by the Jilin Provincial Science and Technology Key Project (20150204040GX), The Northeast Normal University $2^{\text {nd }}$ Batch Project of Network Aided Teaching Course (108029068), the Jilin Provincial Education and Teaching Reform Project "Blended and Inquiry Teaching Model for Undergraduate Course Learning (2014NENU) ".

\section{REFERENCES}

[1] Qixian Cai, "CC2004 Computing Curricula System Analysis and Research”, Research in Higher Education of Engineering, 2006 (5), pp. 77-81.

[2] Dexiang Qu, "The Research and Application of Practical Teaching on Algorithm Design and Analysis Course”, Information Technology and Informatization, 2012 (1), pp. 61-63. 
[3] Blackboard Inc. "Blackboard Learn ${ }^{\mathrm{TM}}$ Instructor Guide for Release 9.1”, March 16, 2010.

[4] D.H. Jonassen, J. Howland, J. Moore and R. M. Marra, "Learning to solve problems with technology: A constructivist perspective”, 2nd. Ed. Columbus, OH: Merrill/Prentice-Hall.

[5] Zhixian Zhong and Zhaoxia Liu, "On Learning Process Management for the Distance Learner", Journal of Distance Education, pp. 63-66, 2009 (6).
[6] Tao Xin and Xueyan Li, "Some New Trends in Theoretical Education Evaluation and Educational Practice”, Tsinghua Journal of Education, 26(6), pp. 38-43, Dec, 2015.

[7] Liping Gao, Ya Liu, Dunlu Peng, Qingkui Chen and Chunping Cao. "Research on application of flipped teaching in algorithm design and analysis”, Computer Era, pp. 59-61, 2014 (11). 